\section{KOMPASS}

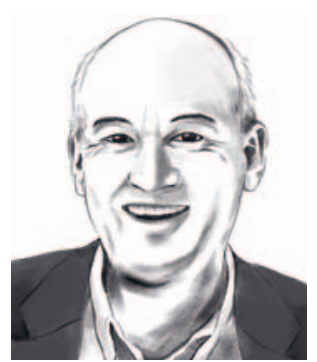

Harald Walach

Poznan/Berlin,

Polen/Deutschland

Mal wieder ein Quiz für Ärzte und Mediziner zur Entspannung: «Was ist die am besten untersuchte und wirksamste Maßnahme zur Verlängerung des Lebens und zur Reduktion vorzeitiger Mortalität?» Nein, weder Schlafen noch die Dauereinnahme von Aspirin, sondern Kalorienreduktion [1, 2]. Dabei scheint es egal zu sein, ob man kontinuierlich ein bisschen weniger isst, als man gerne täte - das ist übrigens auch am schwierigsten - oder ober man immer wieder mal kleine Fastenpausen einlegt. Wichtig zu sein scheint, dass man dem Körper eine metabolische Ruhepause gönnt. Warum ist das so?

\section{«lsst, sterbst, isst ned, sterbst a.»}

Ich denke es hängt damit zusammen, dass jeder Stoffwechselprozess auch Schäden anrichtet, indem er freie Radikale erzeugt, die biologische Strukturen wie Membranen angreifen und die den Körper zu Gegenmaßnahmen zwingen. Es könnte auch damit zusammenhängen, dass Zucker- und Eiweißstoffwechsel gleichermaßen den Insulinausstoß und den Insulin-like growth factor anregen, was beides den Alterungsprozess befeuert. Helmut Qualtinger, der berühmte österreichische Schauspieler, Schriftsteller und Kabarettist, hätte vermutlich gesagt: «lsst, sterbst, isst ned, sterbst a.»

\title{
Lebensverlängernde Maßnahme
}

\author{
Harald Walach \\ Poznan/Berlin, Polen/Deutschland
}

Vielleicht wäre eine Lehre aus der kabarettistischen Weisheit: Mit dem Essen haushalten führt auch zu einer Verlängerung des Lebens (und ist sogar noch billiger; was allerdings vermutlich aufgrund der längeren Lebensdauer nicht so arg ins Gewicht fällt). Das gelingt auf mehrfache Weise: Wir können hin und wieder eine Mahlzeit ausfallen lassen. Etwa den Körper bei seinem natürlichen Fastenprozess, den er über Nacht eingeleitet hat, unterstützen, indem wir das Frühstück verschieben, wenn wir ohnedies ein üppiges Abendessen genossen haben, oder das Abendessen sausen lassen. Auf Neudeutsch heißt das dann «Dinercancelling»; klingt irgendwie besser als «intermittierendes Fasten». Alle religiösen Traditionen kennen die eine oder andere Form des Fastens, bei uns kirchliche Fastentage oder -zeiten. Nur haben wir diese in unserer Gegenwart des Überflusses immer weniger ernst genommen. Vermutlich stammen sie daher, dass unser Nahrungsangebot über den Zeitraum der Evolutionsperiode bis vor Kurzem begrenzt war. Daher macht man doch lieber gleich aus der Not eine Tugend. Und über die langen Jahrhunderttausende hat unser Organismus gelernt, gut mit Mangel umzugehen, kommt aber nur sehr schlecht mit Überfluss zurecht. So stammen wir alle von solchen Stammeseltern ab, die Mangel überstanden haben. Sonst wären wir nämlich nicht hier.
Ich war mal ein paar Tage Gast in einem Kartäuserkloster, als ich mich mit einem Kartäuserschriftsteller beschäftigt habe. Dort essen die Mönche einmal um 10 Uhr vormittags, und einmal nachmittags um 16 Uhr. Wenn Fastenzeit ist, also von September bis nach Ostern, essen sie überhaupt nur einmal richtig und am Nachmittag allenfalls sehr wenig, etwa Salat. Das dürfte der alten Tradition geschuldet sein, dass es eben früher im Winter weniger zu essen gab. Die meisten dort, so hörte ich, werden steinalt und brauchen wenig medizinische Versorgung.

Wir müssen ja nicht gleich alle Kartäuser werden, aber die Reduktion der Nahrungszufuhr in einem institutionalisierten Rahmen scheint keine dumme Idee zu sein. Dreimal essen müssen vermutlich nur Forst- und Bauarbeiter. Und Kinder. Und wenn wir uns nicht mit gezuckerten Snacks und Getränken unsere Insulinschaukel anwerfen, können wir unseren Organismus mit etwas Geduld dazu erziehen, über längere Strecken mit weniger besser zu leben. Das wäre vermutlich auch ein gutes Rezept für andere Lebensbereiche, aber das steht auf einem anderen Blatt.

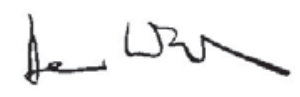

Prof. Dr. Dr. phil. Harald Walach

\section{Literatur}

1 Fontana L, Hu FB: Optimal body weight for health and longevity: bridging basic, clinical, and population research. Aging Cell 2014;13:391-400.
2 Fontana L, Partridge L, Longo VD: Extending healthy life span - from yeast to humans. Science 2010;328:321-326.

\section{KARGER}

Fax +497614520714

information@karger.com

www.karger.com

\section{(c) 2018 S. Karger GmbH, Freiburg}

Accessible online at: www.karger.com/kop
Prof. Dr. Dr. phil. Harald Walach

CHS Institut

Schönwalder Straße 17

13347 Berlin, Deutschland 